\title{
The Role of First Language Facilitators in Redefining Parent Involvement: Newcomer Families' Funds of Knowledge in an Intercultural Preschool Program
}

\author{
Christine Massing, Anna Kirova, and Kelly Hennig
}

Christine Massing is a fourth-year doctoral student in the department of elementary education at the University of Alberta, specializing in early childhood education. She also instructs in the early learning and child care program at Grant MacEwan University. Her doctoral research focuses on immigrant and refugee women's knowledge construction in early childhood teacher education programs. Email: christine.massing@ualberta.ca

Anna Kirova, $\mathrm{PhD}$, is professor of early childhood education at the University of Alberta. Her research interests include understanding culturally and linguistically diverse children's experiences of loneliness and isolation at school, and the possibility such an understanding offers for culturally sensitive pedagogy. Most recently, her research focuses on collaborative research with children, use of arts-based methodologies with vulnerable children, and community-based participatory research aimed at developing an intercultural early learning program for immigrant and refugee children in which children maintain their home language and culture while learning English. Email: anna.kirova@ualberta.ca

Kelly Hennig has worked in a variety of roles for Edmonton Head Start programs over the last 16 years. He has worked as an early learning teacher, a Head Start supervisor and a planning and evaluation coordinator. He is currently a senior manager with the Alberta Ministry of Education. His work has included planning for responsive program delivery, developmental evaluation, and policy development. His research interests include exploring alternative means of representing young children's learning, and social policy related to poverty reduction. Email: kelly.hennig@gov.ab.ca

Involving immigrant and refugee families is a desirable goal of ECE programs in Canada; however, families are typically brought into a prescriptive, defined space framed by Euro-North American standards of developmental appropriateness. Within this space, immigrant and refugee families' funds of cultural knowledge are systematically marginalized. An intercultural preschool program, in which English was the common language alongside three other languages, aimed at enhancing the children's knowledge and pride in their home languages and cultures; the program challenged the conventional view of parental involvement. First language facilitators and cultural brokers acted as conduits between home and preschool and supported social networking within each of the three cultural communities represented in the program. Drawing on data collected through ethnographic methods during a unit on babies as part of an emergent curriculum, the authors describe how the facilitators and brokers brought newcomer families' knowledge funds into the classroom and curriculum, resulting in a culturally sustaining pedagogy.

\section{Acknowledgments}

The authors gratefully acknowledge the Community Partnership Enhancement Fund (CPEF) and the Alberta Centre for Child, Family, and Community Research (ACCFCR) for their generous support of this research.

\section{Barriers to Involving Immigrant and Refugee Parents}

Involving families is a desirable goal of early childhood education (ECE) programs in Canada; however, immigrant and refugee families that are brought into a prescriptive, defined space framed by Euro-North American standards of developmental appropriateness encounter a number of challenges. Within such a space, newcomer families' funds of linguistic and cultural knowledge are systematically marginalized. Tara, now a young adult who works as a Kurdish first language facilitator (FLF) in the intercultural preschool program this article describes, speaks of her family's experience of coming to Canada as non-
English speaking refugees from Kurdistan:

My brother was in day care when we came here. He went through the whole system. It would have really, really helped him and it would have really helped my parents' confidence if the teachers were saying to my parents, "Come, be involved, be part of the school" because a lot of time they felt like strangers to the school and they didn't understand why other parents were involved and they weren't and they didn't know how and what steps they should be taking. (focus group discussion, May 20, 2009)

For immigrant and refugee families with young children, ECE programs are often the first point of contact with the formal educational structures of the dominant culture (Adair, 2009). Like Tara's family, many are unsure of how to navigate the child care system, particularly if such programs do not exist in their home country. Feeling intimidated by the school system is one of many barriers to involvement in ECE programs and schools that immigrant and refugee families report (Turney \& Kao, 2009). Others include 
linguistic differences, lack of program or school support (Song \& Wang, 2006), teacher bias or other discrimination issues (Ali, 2012; Eberly, Joshi, \& Konzal, 2007), not understanding program/ school expetctations for involvement (Bernhard, 2010), holding different views of education and the parental role (Adair, 2009; Ali, 2012), and lack of material resources and/or time (Souto-Manning \& Swick, 2006).

\section{Dominant Views of Culturally Diverse Families}

Majority-culture early learning programs typically consider cultural difference as a deficit instead of an asset. For example, the current position statement of the globally influential American organization, the National Association for the Education of Young Children (NAEYC), describes "children of color, children growing up in poverty and English language learners" as "at risk," possessing "deficits," and "lagging" behind their peers in foundational skills needed for academic achievement (National Association for the Education of Young Children, 2009, p. 6). By extension, these children's families are also depicted as deficient and in need of learning the right way to be and behave in their new context (Lightfoot, 2004; SoutoManning \& Swick, 2006). This attitude undermines newcomer parents' sense of competence in raising their children and may lead to the loss of parenting selfefficacy among immigrant parents (Ali, 2008).

As a consequence, O'Connor (2011) asserts, "the power base which determines which people are more likely to be successful in life is uneven right from the start as children start school with hugely different amounts of the 'right' kind of cultural capital" (p. 117). Families from diverse cultural, racial, or linguistic backgrounds or of low socioeconomic status are perceived to lack this capital (Carreón, Drake, \& Barton, 2005) due to the lack of congruence between their familial culture and that of the dominant society (Lee \& Bowen, 2006). In addition, newcomer families frequently do not possess the resources, skills, and familiarity with the dominant social arrangements in schools to acquire and activate this "right kind" of capital (Lareau, 2000; Levine-Rasky, 2009). Since preservice teachers are educated into a developmental framework based on research with Western, white middle-class children, the cultural capital of immigrant families is largely invisible or inaccessible to them (Bernhard, 2010). The "right kind" of capital is often reflected in curriculum, pedagogy, and assessment (Genishi \& Goodwin, 2008); therefore, young children from such backgrounds continue to be viewed as inadequate in relation to preset developmental norms and expectations (Yosso, 2005). The typical societal response is to offset such "disadvantage" through interventions aimed at building up the "right kind" of cultural capital these children are perceived to need to succeed in school.

\section{The Dilemma Faced by Educators}

Educators feel challenged to respond to the cultural diversity in their classrooms and to communicate to the parents what their children need for school success while remaining true to cultural competence as one of their professional standards. The NAEYC (2009) standards, for instance, emphasize knowing the characteristics of diverse families and communities, building respectful and reciprocal relationships with families, linking language and culture to the program, and maintaining continuity between home and program practices. However, educators must also meet standards related to knowledge of Western child development theories and use interactional, instructional, and assessment approaches consistent with these theories. The tension between what teachers perceive to be their role and the lack of adequate knowledge of particular cultural practices is expressed in the following statement made by a centre director who participated in Reedy and McGrath's (2010) study of child care centres' communications with parents in the USA:
The whole issue of cultural sensitivity/ diversity really complicates the situation. A big part of our role is to honour and support the original culture of the family, the original language and all that. So there is the gray area between what we might make recommendations of what we think is best but might be in conflict with their own cultural belief system. And there are a lot of places where I do not have the answer. (p. 353)

Teaching guides such as NAEYC's (2009) developmentally appropriate practice (DAP) contribute to this dilemma. Preschool teachers' uncertainty with regard to individual families' cultural practices is often resolved by their reliance on prescriptive ways of interacting with families, including asking parents to volunteer in the classroom, to read developmentally appropriate children's books to individual children or the whole group, or to engage in play using developmentally appropriate materials and toys that will help their children reach the development milestones. Although the notion of partnership and equality with parents is emphasized in ECE, the DAP framework positions teachers as experts holding specific professional knowledge, especially that of child development (Alasuutari, 2010). Adair (2009) found that teachers sometimes even "train parents in its principles," reshaping their culturally formed ways of being with their children (p. 154).

\section{The Dominant Framework of Parent Involvement in ECE Settings}

Family involvement in ECE settings is typically conceived in a uniform manner, one that brings families into spaces - which have been defined, and are controlled, by teachers and programs or schools - as volunteers or for meetings and conferences. Within this dynamic, parental involvement inevitably becomes an unquestioned concession to teacher expectations without regard to the families' sociocultural perspectives. This construction has been problematized for 
construing immigrant families as apathetic (Crozier \& Davies, 2007), focusing on familial deficits rather than strengths (Carreón et al., 2005; Ippolito \& Schecter, 2012), trying to subtly change families (López, Scribner, \& Mahitivanichcha, 2001), failing to acknowledge parents' culturally specific ways of being involved (López, 2001; Carreón et al, 2005), excluding visual and oral traditions of some families (Souto-Manning \& Swick, 2006), and neglecting the ways in which involvement is a social practice impacted by myriad external forces (Barton, Drake, Perez, St. Louis, \& George, 2004). Early childhood programs, even those that require parent participation (e.g., Head Start programs) are sites presenting unique challenges to family involvement. If parents have enrolled their children in early childhood programs in order to go to work, as is often the case, participation within the traditional on-site involvement paradigm is seriously curtailed by familial time restrictions (Morrison, Storey, \& Zhang, 2011). Therefore, it is essential to expand our current conceptualizations of family involvement by diversifying the means, tools, and locations for engagement (Knopf \& Swick, 2008), as well as by developing instructional practices that access families' knowledge funds (Espinoza-Herold, 2007). We contend that new approaches in working with culturally diverse and newcomer families should include cultural brokers whose roles can be defined as "the act of bridging, linking, or mediating between groups or persons [of differing cultural backgrounds] for the purpose of reducing conflict or producing change" (Jezewski, 1990, p. 497).

\section{The Study}

The study took place in the context of an intercultural preschool program aimed at enhancing the children's knowledge and pride in their home languages and cultures. First language facilitators and cultural brokers acted as conduits between home and preschool and supported social networking within each of the three cultural communities represented in the program.

\section{Purpose and research questions}

The purpose of the study described here was to explore ways in which cultural brokers and FLFs in an intercultural preschool program acted as conduits to newcomer families and their cultures. It is built on the premise of a high correlation between a child's educational outcome and his or her environment (i.e., family circumstances, parents' educational level, parent participation, etc.) (Worswick, 2006), thus the role of parents and their communities must be implicated in the whole process of educating children (Harvey \& Houle, 2006). The overall aims of this ongoing longitudinal study are twofold: (1) to identify approaches to working with immigrant/refugee communities and families that strengthen the home language for young English as an additional language (EAL) learners, and (2) to identify approaches to curriculum and pedagogy that lead to genuine inclusion of both newcomer children's home languages and cultural traditions and the English language and Canadian cultural traditions. This paper, however, focuses on the following research question: What is the role of cultural brokers and FLFs in creating a shared space in an ECE classroom that bridges the boundaries between home and school cultures? We argue that, through these cultural agents, families were drawn into the preschool space even if they were unable to be physically present, thus challenging the normative view of what constitutes parental involvement in the preschool setting.

\section{Theoretical framework}

The study is framed by a socioculturalhistorical theory of learning as informed by the work of Vygotsky (1978), whereby knowledge is actively constructed by learners as a result of their interactions with others in meaningful activities in a particular sociocultural context. These interactions are often structured so that more knowledgeable or skilled adults or peers can scaffold the child's learning (Wood, Bruner, \& Ross, 1976) or guide the child's participation in activities valued by the culture (Rogoff, 1990, 1995). More skilled partners often employ culturally specific mediational means, such as technologies, tools, or signs to assist with learning processes, assisting the child to move toward full participation in the activities of the family and community (Lave \& Wenger, 1991). Human actions are also mediated by, and inseparable from, the cultural, institutional, and historical contexts in which they occur (Wertsch, 1991, 1998). It is therefore essential to attend to the various contexts in which children dwell. Understanding families, the skills and knowledges they value, and the ways in which they guide and mediate their children's learning is crucial when they come from diverse cultural backgrounds.

The notion of space, as explained by Barton, Drake, Perez, St. Louis, and George (2004), conveys how people's actions and the roles they enact, events, the rules and expectations for participating in the space, the cultural tools people select and utilize to mediate learning (i.e., objects or artefacts), and signs all operate to define the preschool space. Immigrant children enter into preschool spaces that have already been constructed by actions, events, and tools. Since these are likely to be unfamiliar to them, the relationships between instruction/mediation and development are disrupted. A newcomer child experiences dramatic dissonance between two ways of learning because the language of instruction and patterns of interaction are alien to the child; likewise, the activities taking place in schools do not resemble anything with which the child is familiar (Rogoff, 1990, 2003).

The concept of funds of knowledge is an example of an attempt to construct a bridge between home and school (González, Moll, \& Amanti, 2005). It is premised on the understanding that children learn culturally valued knowledge and skills in the course of their daily lived experiences in familial and community contexts. A household's knowledge funds become part of a cultural "tool kit" which helps 
members negotiate daily life or, in Bruner's (1985) view, understand and master their cultural world. Teachers can gain access to families' knowledges through ethnographic field visits to their homes. If teachers are willing to learn from and genuinely collaborate with families, then these knowledges become resources that can mediate teachers' understandings of the household and inform pedagogical theory and practice (Moll, Amanti, Neff, \& González, 2005). For immigrant and refugee families, whose cultural knowledges are systematically marginalized in DAP-centred early childhood settings, this concept has particular resonance. When these understandings are formally acknowledged and reenvisioned as a source of strength in the preschool, it disrupts the traditional, asymmetrical power structures among the family, the ECE program, and the child (González, 2005).

In the study presented here, the FLFs and cultural brokers traversed the borders between home and preschool, moving between the two locations and bringing knowledges and cultural practices and objects from one to the other. Not only did the FLFs and brokers mediate between home and preschool, but they assisted with the formation of social networks within each of the three cultural communities involved in the study. These exchanges helped preserve historically and culturally formed, socially transmitted funds of knowledge (Vélez-Ibáňez \& Greenberg, 2005) which may have been eroded during immigration.

\section{Setting and participants}

As noted elsewhere (Dachyshyn \& Kirova, 2011; Kirova, 2010), the intercultural preschool program described in this paper was instigated by several notfor-profit organizations working closely with immigrant and refugee communities, who then partnered with the public school board, the provincial government, community stakeholders, and university researchers. Children from three refugee communities-Sudanese, Somali, and
Kurdish-attended the program four mornings a week for two and a half hours a day in a public school classroom. Through the process of establishing a parenting group at a family support centre, these three communities had already formed intergroup relationships, and they approached the public school district with the request to offer an early learning program that would meet their specific needs (see Dachyshyn \& Kirova, 2011). However, as the program became well established and known among other refugee communities, over 60 families from Iraq, Serbia, China, and El Salvador, to list a few, as well as the Canadianborn families in the neighbourhood, have been served by the program in the last five years of its operation. Nevertheless, the majority of the children are from the three ethnolinguistic communities: Sudanese Arabic, Somali, and Kurdish. The program staff consists of an Englishspeaking Canadian certified teacher and three first language facilitators (FLFs), each speaking English and at least one of the languages of the ethnolinguistic groups and having some previous experience working with young children. The role of the FLFs was to speak their home language with the children from their language group, to give cultural input for planning, and to provide a link to the families. Some of these facilitators also worked for the founding agency as cultural brokers who visited families multiple times in the home, at school, and at other locations, such as at an appointment (Ford \& Georgis, 2011). During these visits, the cultural brokers provided families with a comprehensive array of linguistic and adaptive supports including community resources and supports for basic needs, advocacy, school, health, education, employment, communication, and parenting (see Ford $\&$ Georgis, 2011). In essence, the cultural brokers served as substitutes for the extensive community support network the families would have had "back home" but lacked in the new context; they acted as elders closely involved with raising the children. Several other cultural brokers from the agency (called "community insiders" by other researchers, including
Ippolito, 2012, p. 4) also worked closely with the project.

Data collection and analysis

This qualitative study primarily utilized ethnographic research methods (LeCompte \& Schensul, 2010). Data were collected in multiple ways in the course of sensory, first-hand experiences in the natural setting (the classroom) in which the phenomena occurred (LeCompte \& Preissle, 1993). The researchers were positioned both as participant observers ensconced within the daily classroom activities and as facilitators and advisors.

Focus groups (Bloor, Frankland, Thomas, \& Robson, 2001) were conducted with three groups of participants: (1) the community members and parents of the children enrolled in the intercultural early learning program at the research site; (2) the classroom teacher, the FLFs, the cultural brokers, and the school administrators at the research site; and (3) all stakeholders, including communityserving agencies and policy makers. Other sources of data during focus groups included field notes taken during and after the focus group.

Focused observations aimed at describing and recording classroom behaviours and practices as they occurred, as well as giving and receiving feedback, reflecting and setting goals for improvement, and suggesting modifications to behaviours/ practices. Detailed field notes were taken during and after these observations.

Research conversations (Herda, 1999) allowed for participants from diverse cultures to work together and assess their actions. These conversations were ongoing and were initiated by both the participants and the researchers. They mostly took place during the regular Monday morning sharing and curriculum planning that involved all FLFs, the teachers, representatives from the not-for-profit organizations, and the university researchers. It was through these conversations of the classroom team that life stories became interconnected in 
a shared understanding about the children in the program and the diverse worlds they needed to know and navigate on a daily basis. In the absence of a set curriculum, Grumet (1995) describes conversation [as] "the process of making sense with a group of people of the systems that shape and organize the world that we can think about together" (p. 19). Taking a constructivist viewpoint, Bruner (1987) defines world-making, or life-making, as "a process in which the life-stories of those involved must mesh, so to speak, within a community of life stories; tellers and listeners must share some 'deep structure' about the nature of "life"' (p. 21).

The FLFs and cultural brokers assisted the researchers in observing appropriate cultural protocols in the discussions with members of their communities (Schensul, Schensul, \& LeCompte, 1999). As primary contacts with the families, they were also able to bring information from their home visits into these discussions. Finally, cultural artefacts, such as cooking and other kitchen utensils, baskets, and musical instruments (see Hennig \& Kirova, 2012) brought into the classroom space by the FLFs and used on a regular basis by the children and the classroom staff were significant data sources, providing insights into cultural values and beliefs. The cultural brokers and FLFs were instrumental in obtaining informed consent for children's, parents' and community members' participation in the research aspect of the program.

Focus group discussions, videotapes, and research conversations were transcribed verbatim and translated by the FLFs as needed to check the accuracy of the participants' statements. Thematic data analysis of the research conversations, field notes, and interview and focus group data involved indexing, assigning codes to common viewpoints, management, combining similarly coded data into categories and clustering like categories from each of the data sources, and interpretation (Creswell, 2005). The FLFs assisted in deciphering the meanings and cultural intent of observed behaviours in videotapes. Data analysis was a recursive process.

\section{Learning Alongside the Brokers and FLFs}

\section{Challenges to involving families}

It was originally hoped that families would be directly and consistently involved in programming and classroom activities. However, due to various barriers faced by the families (transportation, child care, multiple low-paying jobs, attending ESL classes during the day, and so on), the program needed to focus on engaging communities and involving families in ways not defined by "middle-class terms" (settlement worker meeting, October 2, 2008). Some parents attended evening meetings but, for the most part, the teacher did not have contact with families because the children took the bus to the preschool. Considering the unique circumstances of the refugee families meant that parental and community involvement in the program's design was mainly through the ongoing participation of the FLFs and cultural brokers. They offered rich and diverse perspectives on the children's lived experiences and the funds of knowledge formed in home and community contexts, thus creating conditions for learning (Vonta, 2007). In this paper, we focus on three specific ways in which the FLFs and cultural brokers brought parental knowledges and perspectives into the preschool: (1) knowledge of home realities and traditions; (2) purposeful inclusion of everyday cultural objects; and (3) modelling the use of home languages. For the purposes of continuity, the examples have been drawn from a long-term unit on babies.

\section{Knowledge of home realities and traditions}

First of all, the FLFs and brokers possessed firsthand knowledge of the families' cultural traditions and the realities of their day-to-day lives. Not only did they come from the same cultural groups and geographical locations "back home," but they belonged to the same communities here in Canada. Their contacts with one another were often both formal-as cultural brokers - and informal - through community events, kin connections, and mutual friends. Knowing the families in these ways helped FLFs share insights with the teacher which could be incorporated into the planning. From her outside connections to the family, for example, Maryam, the Somali FLF/broker, knew there was a new baby in Amina's family even though Amina "doesn't talk much" about it. She also noted that three of the other families had recently had babies, too. She observed that the recent births might explain why "they are playing babies a lot in the classroom." Since the teacher seldom had direct contact with parents, she might not otherwise have had this information.

Although most ECE teachers consistently observe children to better understand their interests and knowledges, unless the teacher and children have a shared cultural background, it is sometimes challenging to accurately interpret immigrant children's actions. Since the FLFs and brokers were from the same cultural backgrounds as the children, they were especially attuned to their culturally formed practices. As Tara assured us, "If we listen, children will show us what they need to learn." Typically, the children demonstrated what they already knew, and then the FLFs were able to build on their knowledge in the classroom in culturally specific ways. For instance, as the team discussed the children's play, Tara noted, "It is interesting how they are very observant and they know how to take care of the baby and hold the baby." The children were frequently observed enacting cultural scripts around tea ceremonies or parties, both with and without the babies (field notes, September 22, 2009; October 13, 2009). Tea making and tea ceremonies later became a curricular focus with the support of the FLFs (Kirova, 2010). At this point, though, the FLFs were able to serve as interpreters of cultural practices, providing the teacher with information which would not otherwise have been accessible to her. 
The facilitators described how the babies' arrivals might be celebrated in the three cultures. These details deepened the teacher's understanding of cultural practices and enriched the programming. As the teacher, researcher, and FLFs collaboratively brainstormed a unit on babies, for example, they produced a planning chart which combined typical ECE experiences (interpreted according to the children's cultures) with more culturally specific experiences. Maryam stressed that even though the Kurdish, Somali, and Sudanese communities had some similarities, there were also differences in the "little details." However, the facilitators concurred that after a birth, there would be many visitors to the homes and that these visitors would prepare food to bring along. In the Somali tradition, Maryam explained, a gathering would be held prior to the baby's birth, which was

kind of like a shower, but it was different because the family cook food and all the ladies - the neighbour and the relative and the friend bring the family...they are not bringing any gift but food, whatever kind of food they prepare in their own home. (focus group discussion, May 20, 2009)

The facilitators also shared naming traditions. Achi explained that Sudanese parents give their babies names after seven days, and often the baby would be named after the grandparents. Tara added that in Kurdish culture, the baby's name was often related to "meaningful things that's going on in their life." She suggested that we ask parents about name songs and meanings of their children's names and then sing a song for each of the children. These name songs are often sung to the children by adults, such as grandmothers or mothers, and they highlight the child's characteristics and the adults' hopes for them. Achi shared several Sudanese name songs with the group. Then we conferred on how to co-construct similar songs with the children or elicit such songs from the families themselves. Some of the FLFs' suggestions were similar to those commonly used in Canadian ECE settings. For example, Tara emphasized that the parents could be asked to send in baby photos of their children which would "involve parents and show them we appreciate their children" (focus group discussion, May 20, 2009). Maryam wondered about inviting mothers to bring in their babies and offered to help facilitate this contact. The final planning web included such experiences as asking the families to send in baby pictures, bathing and dressing the dolls, asking one of the new mothers to bring in her baby, visiting and bringing food before the baby's birth, gatherings, making sacrifices, offering prayers, name songs and naming traditions, traditional lullabies, and giving gifts to charity or to the family. The FLFs provided a bridge between the usual "Canadian" practices and those of their own cultures. Many of these proved to be somewhat similar, though they were reinterpreted according to the traditions of the culture, allowing children to enact what they were seeing in home, community, and school.

As the FLFs explained traditions from their home countries, it gave the teacher and researchers a better sense of the specific stresses the families might be experiencing in Canada, particularly because of the lack of extended family and community support. Maryam further described the "shower" in the Somali tradition:

When we have a new baby, it's a big event in the community.... They pray and eat and pray for her to have healthy baby and, you know, to be 'four eyes' - the mom has two and the baby has two.... For 6 weeks after the new baby is born the mom is treated like a queen. Her only jobs are to eat, sleep, and breastfeed the baby. New moms don't have problems with postpartum depression because they are surrounded by people all the time. It's our way of showing our happiness and of teaching her if she's a new mom. (focus group discussion, May 20, 2009)
In Kurdish families, there is similar support because, as Tara explained, babies "don't leave the house for 40 days.... they want them familiar with the house before they take them somewhere else" (focus group discussion, May 20, 2009). Cultural practices, the brokers recognized, do not remain static, nor are they transplanted from one place to another. Since most of the families did not have extended family in the city, brokers, as community members, provided links to other families and assisted in constructing these kinds of support networks. Immigrant and refugee families often lack these relationships and connections to others (Suárez-Orozco \& Suárez-Orozco, 2000; Vandenbroeck, Roets, \& Snoeck, 2009). Maryam acknowledged this cultural change as she explained that "now we don't have grandmothers and grandfathers so we help each other" (focus group discussion, May 20, 2009). When someone helps the family navigate the new culture, it also might allow them to access the rules of that culture (Delpit, 2006) and share "resources for action" (Graue, Kroeger, \& Prager, 2001, p. 486). López et al.'s (2001) research found that meeting the multiple needs of families is essential to involving them, but one must first understand what they might be experiencing. This understanding assisted the facilitators and teacher in working with the families as they helped families cope with change. Together they co-created new cultural processes (Rogoff, 2003).

Purposeful inclusion of everyday cultural objects

ECE programs conventionally honour the children's diversity by bringing in cultural objects, particularly in the dramatic play area. However, without knowing the families, it is often very challenging to ascertain which objects are commonly used in their homes, where to locate and purchase such objects, and how to model their use appropriately. In the absence of such knowledge, cultural objects brought from different parts of the world by parents of children previously enrolled in the program, or accumulated by the 
teachers themselves during their travels, serve as "decoration." In contrast, in the classroom in which the study took place, the facilitators, drawing on their personal relationships with the families, were able to bring in the same cultural artefacts the children would have seen at homesuch as traditional slings, rattles, kitchen implements, and cradles - to support the children's play. These artefacts served as cultural tools, mediating the children's learning in a manner which resonated with home (Hennig \& Kirova, 2012). Figures 1 and 2 show the children preparing to put the baby to sleep in the cradle, and carrying the baby in it.

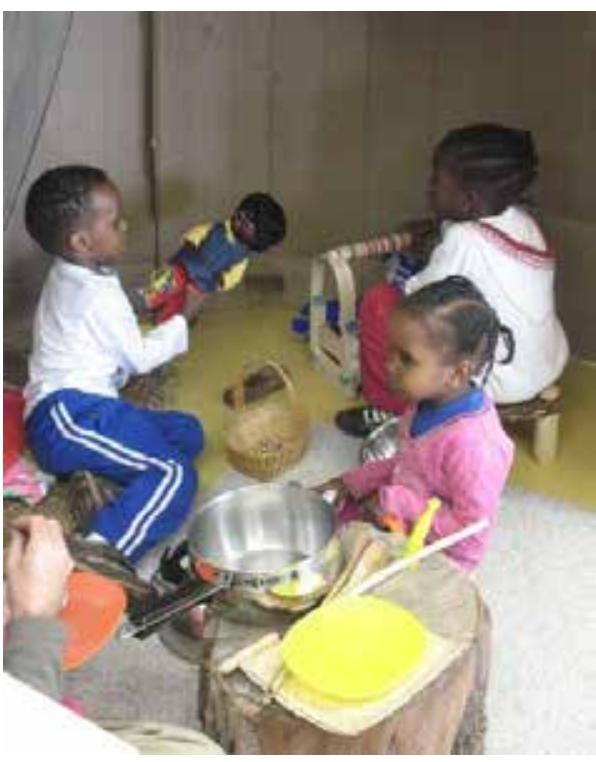

Figure 1. Time to put the baby in the cradle.

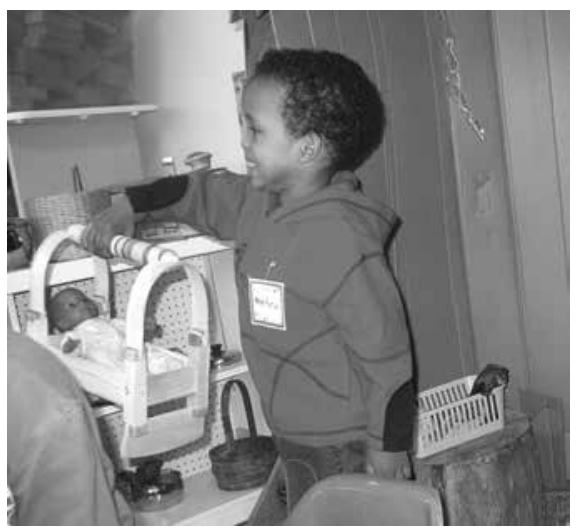

Figure 2. Ali carries the baby in the cradle.

Once these familiar cultural objects were introduced into the preschool room, the children were able to bring their home knowledges into their play. For instance, during one play episode, Yasmin moved from making soup to feeding the baby doll:

Yasmin held the baby in her lap to feed her with the special "baby fork." I (researcher) asked her if the babies eat soup, but she replied, "No, babies only eat cereal." As I began to use a large fork to feed a different baby, she corrected me by giving me a baby fork. Then Amina joined the play. The girls fed the babies and gently put them to sleep in the cradles. Yasmin exhorted us to be quiet. Even when we spoke quietly we were told to "stop it" because "the baby is sleeping." Once her baby woke up, she again picked her up and cradled her as she sat. At that point Amina took the opportunity to place her baby in the cradle. As Amina moved her baby into the cradle, Yasmin perked up from her seat, saying "Don't pick to baby's neck" ("don't pick the baby up by the neck"), demonstrating that she was the one with extensive knowledge about how to care for the babies. Amina conceded and took more care with the baby. When I spoke with Maryam about Yasmin's proficiency, she commented that "depending on the household," even the very young children observed their mothers carefully to learn these skills. (field notes, October 27, 2009)

One of the Somali boys, Jamal, played alongside the girls, making food and then feeding his baby (a "Diego" doll). Maryam commented that such actions would not be "his job" in her culture, but that some Somali husbands begin to take on traditional female roles here in Canada. By involving their children in the activities of daily life, parents guide them in learning specific skills and how to use cultural tools valued by the family and community, but these sometimes change in the new context (see Rogoff, 1990). The FLFs integrated these knowledge funds in their teaching, modelling aspects of care and use of materials that resonated with familial and cultural practices.

In Figure 3, Achi demonstrates how to soothe the baby to sleep.

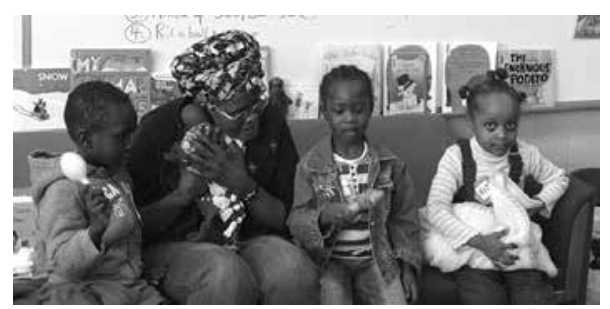

Figure 3. Soothing the baby.

Demonstrations such as these often incorporated artefacts, such as a traditional rattle which was used in conjunction with the song.

\section{Modelling the use of home languages}

Perhaps the most important way in which the FLFs integrated home knowledges into practice was through sustained and intentional use of home language in the classroom space. Each of the FLFs communicated with children from their own cultural background in their home language and spoke English with the children belonging to the other two linguistic/cultural groups. Guided by the children's interests and the focus on babies and naming, the FLFs showed children how to write their names in their home languages. The FLFs, teacher, and researchers also identified key vocabulary words in each of their respective home languages to support the programming. Culturally relevant vocabulary was relayed to the children by the FLFs, in particular through stories and songs, such as lullabies and naming songs. In a series of focus group discussions with parents, cultural brokers, community leaders, and elders, it became clear that, for them, learning happens through observing and participating in life, and that teaching respect for family members and elders in the community is a priority. Therefore, instead of using Western approaches to teaching young children vocabulary, descriptions, labelling of objects, questioning, or extensive "talk," traditional songs were used to instruct, to 
convey important words of wisdom in the contexts in which they would normally be used (see Hennig \& Kirova, 2012). As a result, the children used the target vocabulary in the context of their play. For example, during a play episode in which she prepared food, Yasmin proudly informed us that she knew how to say spoon and pot in Somali (field notes, October 13, 2009).

The FLFs demonstrated that they were particularly adept at including the children's and, by extension, the families' perspectives. In a circle time activity, each FLF shared lullabies in their first language and ways of soothing babies to sleep, then invited children to sit with them to sing. In one instance, Maryam began to sing a lullaby and one of the boys spoke out, saying "No, it's not like that." Rather than correcting the child, Maryam stated, "That's a song your mom's doing right now." She encouraged him to come up and share his family's version (field notes, December 15, 2009). Some of the other children who had babies at home clamoured to come and sing with Maryam in the manner they had learned from their own mothers. The playful and participatory nature of the circle time was a typical example of the mutual contribution of all participants, not just the adults. Therefore, the familial perspectives were expressed and shared by way of the FLFs, who lived and worked in both worlds as trusted members of the cultural community and as members of the school community.

Figure 4 shows Maryam singing with Amina and her "baby."

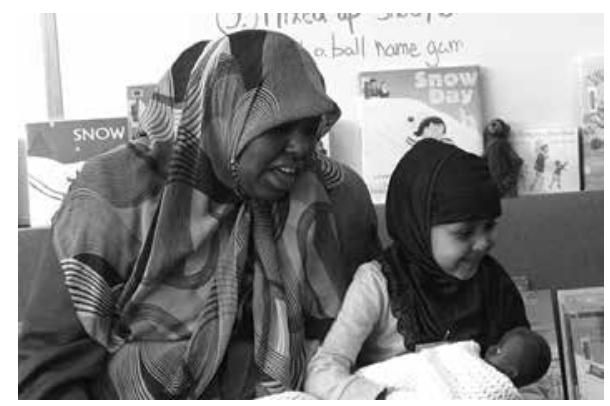

Figure 4. Singing to the baby.

Discussion
The concept of hospitality, which is sometimes invoked in literature on family involvement (Barone, 2011; Lahman \& Park, 2004), might imply that families are guests to be welcomed into the preschool space rather than partners in constructing it (Carreón et al., 2005). Adair's (2009) research with immigrant and non-immigrant preschool teachers proposed that teachers make "contextbased decisions about how to work with children of immigrants and their families" (p. 192). Often this context is that of the dominant culture, reflecting the teacher's own past experiences and interactions rather than those of the family and community. When the teacher lacks cultural awareness and knowledge, her or his biases inhibit communication with families (Eberly et al., 2007) and planning may be operationalized in the form of a cultural tourism approach (Strickland, Keat, \& Marinak, 2010).

In reviewing the body of work that has been done based on conceptualizations of resource pedagogies-including funds of knowledge (Moll \& Gonzalez, 2005), culturally relevant pedagogy (LadsonBillings, 1995), funds of knowledge and third space (Gutiérrez, Baquedana-Lopez, \& Tejeda, 1999)_Paris (2012) argues that such approaches "do not explicitly enough support the linguistic and cultural dexterity and plurality (Paris, 2009, 2011) necessary for success and access" in schools and communities (p. 95, italics in original). He offers the term culturally sustaining pedagogy as an alternative that builds on these resource pedagogies. This pedagogy maintains both the traditional and the evolving ways in which young people live in contemporary multilingual, multiethnic, and multicultural societies. It affirms that pedagogical approaches should "support young people in sustaining the cultural and linguistic competence of their communities while simultaneously offering access to dominant cultural competence" (p. 95).

The study briefly described here, we believe, is an example of such culturally sustaining pedagogy because the FLFs served as mediators of home practices as they entered the classroom. The children in the program were able to bring the collective (cultural) knowledge they first learned by participating in family and community practices into the classroom, where this knowledge was transformed into personal competence. Children's knowledge of "event structures" (Nelson, 1995) such as feeding a baby, soothing a baby with a lullaby, cuddling a baby, putting the baby in a crib, and so forth is necessary for children to acquire categories and language. According to Nelson (1974), young children's concept formation is a process of acquiring knowledge through the child's actions and interactions in specific types of situations. What the child learns in these everyday practices also depends on the objects that adults make available in any given situation (Rogoff, 1990). Consistent with sociocultural approaches to learning, the program recognized that development occurs largely through everyday activities and interactions of individuals and their social partners (Tudge \& Odero-Wanga, 2009). These interactions were facilitated by the inclusion of cultural artefacts that were connected to the children's lives outside of the classroom and had significance to the members of the classroom community (Holzman, 2009). Thus, having cultural artefacts in the children's dramatic area was not simply an act of recognition and appreciation of diversity. Rather, it was an essential element of the classroom environment that allowed children from diverse backgrounds to enact their cultural knowledges. Providing cultural objects in the classroom play area, alongside objects typically found in ECE settings, enabled children to continue to appropriate cultural knowledge while guided by more knowledgeable members of their cultural group (i.e., FLFs and cultural brokers) in the process of transition to the new school context. Moreover, through the teacher and more "Canadian" artefacts and practices, the children concurrently gained competencies within the dominant culture (Delpit, 2006; Paris, 2012).

Vygotsky's theory of concept formation, according to which everyday concepts associated with home and community life and scientific concepts associated 
with school life are preconditions for each other, helps us realize that knowing what is happening in children's lives and their families' and communities' cultural practices goes far beyond what the prevalent early childhood "parent involvement" practices entail. In the case of newcomer children, in particular, the theory implies that if the spontaneous everyday concept formation is interrupted as the child enters school, then the scientific concept development built on everyday concept development is also interrupted. This study affirms that the use of cultural brokers and FLFs supports children's everyday concept development based on their families' cultural practices, so these were "present in their parents' absence" (see Vandenbroeck, Roets, \& Snoeck, 2009). This presence ensures continuity of children's learning and concept development. Since the facilitators were present in the families' home lives, they carried parental (and cultural) expectations and ways of being with children into the classroom space. These facilitators deeply enriched the planning process, supporting the funds of knowledge developed in home and community and providing materials and play experiences that not only resonated with the children and allowed them to enact real events in their lives, but also allowed them to acquire the home language vocabulary and cultural practices associated with the events. Although the example provided here cannot necessarily be applied to all immigrant groups, it demonstrates one possible means by which newcomer families can contribute to their children's education apart from the Western model of parental involvement.

\section{Implications for Practice}

Unfortunately, many programs do not have access to full-time, on-site cultural brokers or first language facilitators. There are other means, however, by which programs and teachers can deepen their understanding of immigrant families' funds of knowledge. Initial home visits are, of course, a very useful tool in getting to know families in the home and community context and eliciting their funds of knowledge, if programs have the resources to support these visits. However, Yin, the director of the immigrant agency partnering in this project, suggested that programs look internally to see if they have staff members from the same cultural backgrounds as the children who can act as resources. She stressed the importance of the initial contacts with parents. A translator - $a$ friend, family member, volunteer, or another parent - can provide "linguistic bridging," not only so that teachers can let families know what to expect in the program, but so that teachers can "listen deeply" to the families' stories and their hopes and dreams for their children. Parents, she believes, should have the opportunity to guide programs as to how to get involved instead of programs imposing expectations on families (interview, May 17, 2009). Tara added that teachers can "educate themselves about the children and where they come from" (interview, May 17, 2009).

As Paris (2012) argues, however, fostering children's home language and "withingroup cultural practices" is only one of the goals of culturally sustaining pedagogy (Paris, 2012). As in the program briefly described here, another goal is to create intercultural space based on "common, across group cultural practices" (p. 95) in which cultures mix and a new culture emerges. The examples provided here demonstrate pedagogical practices that allow both aspects of culturally sustaining pedagogy to develop simultaneously and to inform one another.

\section{References}

Adair, J. K. (2009). Teaching child of immigrants: A multisited ethnographic study of preschool teachers in five U.S. cities. Unpublished doctoral dissertation, Arizona State University, Phoenix (UMI No. 3360743).

Alasuutari, M. (2010). Striving at partnership: Parent-practitioner relationships in Finnish early educators' talk. European Early Childhood Education Research Journal, 18, 149-161. doi: $10.1080 / 13502931003784545$

Ali, M. (2008). Loss of parenting self-efficacy among immigrant parents. Contemporary Issues in Early Childhood Education, 9(2), 148-160.

Ali, M. M. (2012). The shadow of colonialism on relations between immigrant parents and their children's teachers. Alberta Journal of Educational Research, 58(2), 198-215.

Barone, D. (2011). Welcoming families: A parent literacy project in a linguistically rich, high-poverty school.
Early Childhood Education Journal, 38, 377-384. doi: 10.1007/s10643-101-0424-y

Barton, A. C., Drake, C., Perez, J. G., St. Louis, K., \& George, M. (2004). Ecologies of parental engagement in urban education. Educational Researcher, 33(4), $3-12$.

Bernhard, J. K. (2010). From theory to practice: Engaging immigrant parents in their children's education. Alberta Journal of Educational Research, 56(3), 319-334.

Bloor, M., Frankland, J., Thomas, M., \& Robson, K. (2001). Focus groups in social research. London, UK: Sage.

Bruner, J. (1985). Vygotsky: A historical and conceptual perspective. In J. V. Wertsch (Ed.), Culture, communication, and cognition: Vygotskian perspectives, (pp. 21-34). London, UK: Cambridge University Press.

Bruner, J. (1987). Life as narrative. Social Research, 54(1), $11-32$.

Carreón, G. P., Drake, C., Barton, A. C. (2005). The importance of presence: Immigrant parents' school engagement experiences. American Educational Research Journal, 42(3), 465-498.

Creswell, J. W. (2005). Educational research: Planning, conducting and evaluating quantitative and qualitative research. Upper Saddle River, NJ: Pearson Education.

Crozier, G., \& Davies, J. (2007). Hard to reach parents or hard to reach schools? A discussion of home-school relations, with particular reference to Bangladeshi and Pakistani parents. British Educational Research Journal, 33, 295-313. doi: $10.1080 / 01411920701243578$

Dachyshyn, D., \& Kirova, A. (2011). Classroom challenges in developing an intercultural early learning program for refugee children. Alberta Journal of Educational Research, 57(2), 220-233.

Delpit, L. (2006). Other people's children: Cultural conflict in the classroom. New York, NY: New Press.

Eberly, J. L., Joshi, A., \& Konzal, J. (2007). Communicating with families across cultures: An investigation of teacher perceptions and practices. The School Community Journal, 17(2), 7-26.

Espinoza-Herold, M. (2007). Stepping beyond sí se puede: Dichos as a cultural resource in mother-daughter interaction in a Latino family. Anthropology and Education Quarterly, 38, 260-277. doi; 10.1525/ aeq.2007.38.3.260

Ford, D., \& Georgis, R. (2011). An intercultural early learning program: What wraparound support looks like for newcomer families. Early Childhood Education, 39(2), 21-30.

Genishi, C., \& Goodwin, A. L. (2008). Diversities in early childhood education: Rethinking and doing. New York, NY: Routledge.

González, N. (2005). Beyond culture: The hybridity of funds of knowledge. In Norma González, L. C. Moll, \& C. Amanti (Eds.), Funds of knowledge: Theorizing practices in households, communities, and classrooms (pp. 29-46). Mahwah, NJ: Lawrence Erlbaum.

González, N., Moll, L. C., \& Amanti, C. (2005). Introduction: Theorizing practices. In N. González, L. C. Moll, \& C. Amanti (Eds.), Funds of knowledge: Theorizing practices in households, communities, and classrooms (pp. 1-28). Mahwah, NJ: Lawrence Erlbaum.

Graue, M. E., Kroeger, J., \& Prager, D. (2001). A 
Bakhtinian analysis of particular home-school relations. American Educational Research Journal, 38(3), 467-498.

Grumet, M. (1995). Curriculum: What are the basics and are we teaching them? In J. L. Kincheloe \& S. R. Steinberg (Eds.) Thirteen questions: Reframing education's conversations. New York, NY: Peter Lang.

Gutiérrez, K., Baquedana-Lopez, P., \& Tejeda, C. (1999). Rethinking diversity: Hybridity and hybrid language practices in the third space. Mind, Culture and Activity, $6,286-303$.

Harvey, E., \& Houle, R. (2006). Demographic changes in Canada and their impact on public education. Toronto, ON: Learning Partnership.

Hennig, K., \& Kirova, A. R. (2012).The role of cultural artifacts in play as tools to mediate learning in an intercultural preschool program. Contemporary Issues in Early Childhood, 13(3), 226-241.

Herda, E. A. (1999). Research conversations and narratives: A critical hermeneutic orientation in participatory inquiry. Westport, CT: Praeger.

Holzman, L. (2009). Vygotsky at work and play. New York, NY: Routledge.

Ippolito, J. (2012, August). Bringing marginalized parents and caregivers into their children's schooling. What works? Research into practice. Toronto, ON: Literacy and Numeracy Secretariat \& Ontario Ministry of Education. Retrieved from http://www.edu.gov.on.ca/ eng/literacynumeracy/inspire/research/whatWorks.html

Ippolito, J., \& Schecter, S. R. (2012). Using institutional structures to promote educational equity: A tale of two schools. Elementary School Journal, 112(4), 607-626.

Jezewski, M. A. (1990). Culture brokering in migrant farm worker health care. Western Journal of Nursing Research, 12(4), 497-513.

Kirova, A. (2010). Children's representations of cultural scripts in play: Facilitating transition from home to preschool in an intercultural early learning program for refugee children. Diaspora, Indigenous, and Minority Education: An International Journal, 4(2), 1-18.

Knopf, H. T., \& Swick, K. J. (2008). Using our understanding of families to strengthen family involvement. Early Childhood Education Journal, 35, 419-427. doi: 10.1007/s10643-007-0198-z

Ladson-Billings, G. (1995). Towards of theory of culturally relevant pedagogy. American Educational Research Journal, 32, 465-491.

Lahman, M. K. E., \& Park, S. (2004). Understanding children from diverse cultures: Bridging perspectives of parents and teachers. International Journal of Early Years Education, 12, 131-142. doi: $10.1080 / 0966976042000225525$

Lareau, A. (2000). Home advantage: Social class and parental intervention in elementary education. New York, NY: Rowman \& Littlefield.

Lave, J., \& Wenger, E. (1991). Situated learning: Legitimate peripheral participation. New York, NY Cambridge University Press.

LeCompte, M. D., \& Preissle, J. (1993). Ethnography and qualitative design in educational research. New York, NY: Academic Press.

LeCompte, M. D., \& Schensul, J. J. (2010). Designing and conducting ethnographic research. Walnut Creek, CA Altamira.

Lee, J-S., \& Bowen, N. K. (2006). Parent involvement, cultural capital and the achievement gap among elementary school children. American Educational Research Journal, 43(2), 193-218. involvement at a multicultural school. British Journal of Sociology of Education, 30, 331-344. doi: $10.1080 / 01425690902812604$

Lightfoot, D. (2004). "Some parents just don’t care:" Decoding the meanings of parent involvement in urban schools. Urban Education, 39(1), 91-107.

López, G. R. (2001). The value of hard work: Lessons on parent involvement from an (im)migrant household. Harvard Educational Review, 71(3), 416-437.

López, G. R., Scribner, J. D., \& Mahitivanichcha, K. (2001). Redefining parental involvement: Lessons from high-performing migrant-impacted schools. American Educational Research Journal, 38(2), 253-288.

Moll, L., \& Gonzalez, N. (1994). Lessons from research with language minority children. Journal of Reading Behaviour, 26(4), 23-41.

Moll, L., Amanti, C., Neff, D., \& González, N. (2005) Funds of knowledge for teaching: Using a qualitative approach to connect homes and schools. In N. González, L. C. Moll, \& C. Amanti (Eds.), Funds of knowledge: Theorizing practices in households, communities, and classrooms (pp. 71-88). Mahwah, NJ: Lawrence Erlbaum.

Morrison, J. W., Storey, P., \& Zhang, C. (2011). Accessible family involvement in early childhood programs. Dimensions of Early Childhood, 39(3), 21-26.

National Association for the Education of Young Children. (2009). Position statement. In C. Copple \& S. Bredekamp (Eds.), Developmentally appropriate practice in early childhood programs serving children from birth through age 8 (pp. 1-31). Washington, DC: Author.

Nelson, K. (1974). Concept, word, and sentence: Interrelationship in acquisition and development. Psychological Review, 81(4), 267-285.

Nelson, K. (1995). From spontaneous to scientific concepts Continuities and discontinuities from childhood to adulthood. In L. Martin, K. Nelson, \& E. Tobach (Eds.), Sociocultural psychology: Theory and practice of doing and knowing (pp. 229-249). New York, NY: Cambridge University Press.

O'Connor, J. (2011). Applying Bourdieu's concepts of social and cultural capital and habitus to early years research. In T. Waller, J. Whitmarsh, \& K. Clarke (Eds.), Making sense of theory and practice in early childhood: The power of ideas (pp. 115-127). Maidenhead, UK: Open University Press.

Paris, D. (2012). Culturally sustaining pedagogy: A needed change in stance, terminology, and practice. Educational Researcher, 41, 93-97. doi: 10.3102/0013189X12441244

Reedy, C. K., \& McGrath, W. H. (2010). Can you hear me now? Staff-parent communication in child care centres. Early Child Development and Care, 180, 347-357.doi: 10.1080/03004430801908418

Rogoff, B. (1990). Apprenticeship in thinking: Cognitive development in social context. New York, NY: Oxford University Press.

Rogoff, B. (1995). Observing sociocultural activity on three planes: Participatory appropriation, guided participation, and apprenticeship. In J. Wertsch, P. del Rio, \& A. Alvarez (Eds.), Sociocultural studies of mind (pp. 139-164). Cambridge, UK: Cambridge University Press.

Rogoff, B. (2003). The cultural nature of human development. New York, NY: Oxford University Press.
Schensul, S. L., Schensul, J., \& LeCompte, M. D. (1999) Essential ethnographic methods: Observations, interviews and questionnaires. Walnut Creek, CA: Altamira.

Song, S., \& Wang, X. C. (2006). Immigrant parents' involvement in American schools: Perspectives from Korean mothers. Early Childhood Education Journal, 34(2), 25-132.

Souto-Manning, M., \& Swick, K. J. (2006). Teachers' beliefs about parent and family involvement: Rethinking our family involvement paradigm. Early Childhood Education Journal, 34, 187-193. doi: 10.1007/s10643-006-0063-5

Strickland, M. J., Keat, J. B., \& Marinak, B. A. (2010). Connecting worlds: Using photo narrations to connect immigrant children, preschool teachers, and immigrant families. The School Community Journal, 20(1), 81-101.

Suárez-Orozco, C., \& Suárez-Orozco, M.M. (2001). Children of immigration. Cambridge, MA: Harvard University Press.

Tudge, J. R. H., \& Odero-Wanga, D. (2009). A culturalecological perspective on early childhood among the Luo of Kisumu, Kenya. In M. Fleer, M. Hadegaars, \& J. R .H. Tudge (Eds.). The world year book of education 2009: Childhood studies and the impact of globalization: Policies and practices at global and local levels (pp. 142-160). New York, NY: Routledge.

Turney, K., \& Kao, G. (2009). Barriers to school involvement: Are immigrant parents disadvantaged? The Journal of Educational Research, 102(4), 257-271.

Vandenbroeck, M., Roets, G., \& Snoeck, A. (2009). Immigrant mothers crossing borders: Nomadic identities and multiple belongings in early childhood education. European Early Childhood Education Research Journal, 17, 203-216. doi: $0.1080 / 13502930902950452$

Vélez-Ibáñez, C., \& Greenberg, J. (2005). Formation and transformation of funds of knowledge. In N. González, L. C. Moll, \& C. Amanti (Eds.), Funds of knowledge: Theorizing practices in households, communities, and classrooms (pp. 47-70). Mahwah, NJ: Lawrence Erlbaum.

Vonta, T. (2007, August). Vygotsky's ideas in the new democracies. Children in Europe, 21-23. Retrieved from http://www.issa.nl/news/Children $\% 20 \mathrm{in} \% 20$ Europe_August_2007-pages21-23.pdf

Vygotsky, L. (1978). Mind and society: The development of higher mental processes. Cambridge, MA: Harvard University Press.

Vygotsky, L. (1986). Thought and language. (A. Kozulin, Trans.). Cambridge, MA: MIT Press.

Wertsch, J. (1991). Voices of the mind: A sociocultural approach to mediated action. Cambridge, MA: Harvard University Press.

Wertsch, J. (1998). Mind as action. New York, NY: Oxford University Press

Wood, D., Bruner, J., \& Ross, G. (1976). The role of tutoring in problem solving. Journal of Child Psychology and Psychiatry, 17, 89-100.

Worswick, C. (2006). Incidence and persistence of early literacy problems: Evidence from NLSCY, 1994-2000. Final Report. Cat. No. SP-617-04-06E. Ottawa, ON: Human Resources and Skills Development Canada.

Yosso, T. (2005). Whose culture has capital? A critical race theory discussion of community cultural wealth. Race Ethnicity and Education, 8, 69-91. doi:10.1080/1361332052000341006

Levine-Rasky, C. (2009). Dynamics of parent 